\title{
RESEARCH
}

Open Access

\section{Unveiling role of sphingosine-1-phosphate receptor 2 as a brake of epithelial stem cell proliferation and a tumor suppressor in colorectal cancer}

Luciana Petti ${ }^{1}$, Giulia Rizzo ${ }^{2}$, Federica Rubbino ${ }^{2}$, Sudharshan Elangovan ${ }^{2}$, Piergiuseppe Colombo ${ }^{3}$, Silvia Restelli ${ }^{1}$, Andrea Piontini ${ }^{2}$, Vincenzo Arena ${ }^{4}$, Michele Carvello $^{5}$, Barbara Romano ${ }^{6}$, Tommaso Cavalleri ${ }^{7}$, Achille Anselmo ${ }^{8}$, Federica Ungaro 2 , Silvia D’Alessio ${ }^{2}$, Antonino Spinelli ${ }^{2,5}$, Sanja Stifter ${ }^{9}$, Fabio Grizzi ${ }^{10}$, Alessandro Sgambato ${ }^{4,11}$, Silvio Danese ${ }^{1,2}$, Luigi Laghi, ${ }^{7,2}$, Alberto Malesci ${ }^{2,7}$ and Stefania Vetrano ${ }^{1,2^{*}}$

\begin{abstract}
Background: Sphingosine-1-phosphate receptor 2 (S1PR2) mediates pleiotropic functions encompassing cell proliferation, survival, and migration, which become collectively de-regulated in cancer. Information on whether S1PR2 participates in colorectal carcinogenesis/cancer is scanty, and we set out to fill the gap.

Methods: We screened expression changes of S1PR2 in human CRC and matched normal mucosa specimens $[N=$ 76]. We compared CRC arising in inflammation-driven and genetically engineered models in wild-type (S1PR2 ${ }^{+/+}$) and S1PR2 deficient (S1PR2 ${ }^{-1-}$ ) mice. We reconstituted S1PR2 expression in RKO cells and assessed their growth in xenografts. Functionally, we mimicked the ablation of S1PR2 in normal mucosa by treating S1PR2 ${ }^{+/+}$organoids with JTE013 and characterized intestinal epithelial stem cells isolated from S1PR2 ${ }^{-1-}$ Lgr5-EGFP- mice.

Results: S1PR2 expression was lost in 33\% of CRC; in 55\%, it was significantly decreased, only $12 \%$ retaining expression comparable to normal mucosa. Both colitis-induced and genetic $\mathrm{Apc}^{+/ \mathrm{min}}$ mouse models of CRC showed a higher incidence in size and number of carcinomas and/or high-grade adenomas, with increased cell proliferation in S1PR2 ${ }^{-/}$mice compared to S1PR2 ${ }^{+/+}$controls. Loss of S1PR2 impaired mucosal regeneration, ultimately promoting the expansion of intestinal stem cells. Whereas its overexpression attenuated cell cycle progression, it reduced the phosphorylation of AKT and augmented the levels of PTEN.
\end{abstract}

(Continued on next page)

\footnotetext{
* Correspondence: stefania.vetrano@humanitasresearch.it;

stefania.vetrano@hunimed.eu

${ }^{1}$ IBD Center, Department of Gastroenterology, Humanitas Clinical and Research Center-IRCCS, Rozzano, Italy

${ }^{2}$ Department of Biomedical Sciences, Humanitas University, Via Rita Levi Montalcini, Pieve Emanuele, Italy

Full list of author information is available at the end of the article
}

(c) The Author(s). 2020 Open Access This article is licensed under a Creative Commons Attribution 4.0 International License, which permits use, sharing, adaptation, distribution and reproduction in any medium or format, as long as you give appropriate credit to the original author(s) and the source, provide a link to the Creative Commons licence, and indicate if changes were made. The images or other third party material in this article are included in the article's Creative Commons licence, unless indicated otherwise in a credit line to the material. If material is not included in the article's Creative Commons licence and your intended use is not permitted by statutory regulation or exceeds the permitted use, you will need to obtain permission directly from the copyright holder. To view a copy of this licence, visit http://creativecommons.org/licenses/by/4.0/. The Creative Commons Public Domain Dedication waiver (http://creativecommons.org/publicdomain/zero/1.0/) applies to the data made available in this article, unless otherwise stated in a credit line to the data. 
(Continued from previous page)

Conclusions: In normal colonic crypts, S1PR2 gains expression along with intestinal epithelial cells differentiation, but not in intestinal stem cells, and contrasts intestinal tumorigenesis by promoting epithelial differentiation, preventing the expansion of stem cells and braking their malignant transformation. Targeting of S1PR2 may be of therapeutic benefit for CRC expressing high Lgr5.

Keywords: Colorectal cancer, Lgr5, S1PR2, PTEN, Epithelial proliferation

\section{Background}

The sphingosine-1-phosphate (S1P) is a pleiotropic and widespread bioactive molecule belonging to the sphingolipid family, a complex group of lipids present in all eukaryotic cells. Previously considered to play only structural functions, sphingolipids are now recognized as key regulators of a myriad of cellular functions in pathophysiological processes $[1,2]$. S1P receptors 1-3 (S1PR1, S1PR2, and S1PR3) are expressed ubiquitously, whereas the expression of S1PR4 and S1PR5 is mainly confined to the lymphoid, hematopoietic tissue, and central nervous system [3]. The association with different $G$ proteins activate several downstream pathways contributing to the regulation of many cellular mechanisms [3]. Consequently, considerable interest has been devoted to the S1P/S1PRs axis as potential therapeutic targets for the modulation of several cellular processes. The blockade of S1PR1 is emerging as a new therapeutic approach to control the aberrant leukocyte migration into the intestinal mucosa in inflammatory bowel disease [4]. Conversely, the function of other S1P receptors in the gut has received less attention so far. Recent studies demonstrated the involvement of S1P signaling in several types of cancers [5-9], including colon cancer [10-12]. Colorectal cancer (CRC) is a heterogeneous disease in which different subtypes may be distinguished according to their clinical and molecular features [13]. Intestinal stem cells play an important role in CRC pathogenesis due to their pre-existing proliferative and self-healing behavior, suggesting them to serve as the source for most colorectal cancers [14]. Intestinal epithelial cell proliferation and differentiation are driven by intestinal epithelial stem cells located at the base of crypts, which are either active Leucine-rich repeat-containing G-protein coupled receptor 5 positive (Lgr5+) or quiescent (Lgr5-). According to the traditional 'bottom-up' model of CRC development, the transformation of Lgr5+ crypt stem-cells is the principal mechanism initiating the aberrant growth leading to adenomatous polyps, predisposing to cancer [14]. However, the molecular cues driving these events remain to be elucidated.

S1P/S1PR1 axis has been found as a critical key in the link between chronic inflammation and colon cancer by promoting persistent activation of STAT3 in intestinal epithelial cells, which consequently leads to malignant transformation [10]. However, the role of S1P receptors in
CRC remains to be determined. mRNA levels of S1PR1, S1PR2, and S1PR3 expression in CRC patients have scarcely been investigated. The only two studies reported controversial results, possibly due to the limited size and heterogeneity of the cohort of patients analyzed. The first study showed a varied expression profile of all three receptors without any trend along CRC tissues analyzed [15], whereas a second one an increased expression of S1PR2 and S1PR3 in tumor samples compared to normal tissue samples [16].

S1PR2 is a critical receptor for the development and progression of different types of cancers and, although its role is controversial depending on the tissue, most data support an anti-tumor function [17]. Indeed, S1PR2 negatively regulates migration and invasion of human melanoma [18], glioblastoma [19], oral squamous cell carcinoma, and gastric cell lines [11] and cell proliferation in human renal tumor cells [20]. Moreover, the genetic deletion of S1PR2 promoted the growth of melanoma and Lewis lung carcinomas in vivo [21], supporting S1PR2 as a critical regulator of cell proliferation. A recent study has demonstrated that S1PR2 on intestinal epithelial cells regulates epithelial barrier by preventing CD4 + T-cell proliferation [22]. Nevertheless, its function in epithelial cells remains to be elucidated.

In this study, we demonstrated, for the first time, that S1PR2 functions as a brake on the proliferation of intestinal stem cells. Its inhibition bursts epithelial proliferation and promotes tumor development. In human CRC, the expression of S1P2 is drastically reduced, thus unveiling S1PR2 as a new candidate tumor suppressor gene in colorectal tumorigenesis.

\section{Materials and methods}

\section{Human tissue collection}

Frozen tissue biopsies of 5 adenomas, 39 primary adenocarcinomas with stage II/III pT3-T4, and 16 normal tissues were obtained from fresh tissue biobank collection at Humanitas Clinical and Research Center and proceeded for the mRNA and protein extraction. Healthy tissue was collected at a distance of at least $10 \mathrm{~cm}$ from the tumor lesion. No patient had received any therapy before surgery.

The trial set included formalin-fixed, paraffin-embedded tumor specimens from 40 consecutive patients with stage II/III pT3-T4 colorectal adenocarcinoma who underwent surgery and retrieved from the archives of the Department 
of Pathology of Humanitas Clinical and Research CenterIRCCS from 2011 to 2017. No patients received therapy before surgery (Table 1 ).

The external validation set included tissues of stage II colorectal cancer from Tissue Microarray (TMA) 36 consecutive patients who had undergone surgery from 2006 to 2007 at the Digestive Surgery Clinic, Clinical Hospital Center, and Faculty of Medicine, University of Rijeka, Rijeka, Croatia. Exclusion criteria were age less than 18 or more than 75 years. The study was approved by the Ethics Committee of Humanitas Clinical and Research Center-IRCCS (Rozzano, Italy). All patients gave their written and informed consent.

Table 1 Clinicopathologic features of colorectal cancer patients (CRC) of the Humanitas Cohort

\begin{tabular}{|c|c|}
\hline Cases & $40 \mathrm{CRC}$ \\
\hline \multicolumn{2}{|l|}{ Gender } \\
\hline Male & 25 \\
\hline Female & 15 \\
\hline Median age (years, range) & $71(35-81)$ \\
\hline \multicolumn{2}{|l|}{ Site } \\
\hline Colon right & $16(40 \%)$ \\
\hline Colon left & $11(27,5 \%)$ \\
\hline Rectum & $13(32,5 \%)$ \\
\hline \multicolumn{2}{|l|}{ Histology } \\
\hline Mucinous & $2(5 \%)$ \\
\hline Adenocarcinoma & $38(95 \%)$ \\
\hline \multicolumn{2}{|l|}{ TNM staging system } \\
\hline \multicolumn{2}{|l|}{ Primary tumor $(\mathrm{T})$} \\
\hline $\mathrm{T} 1$ & $8(20 \%)$ \\
\hline $\mathrm{T} 2$ & $12(30 \%)$ \\
\hline T3 & $11(27.5 \%)$ \\
\hline T4 & $9(22.5 \%)$ \\
\hline \multicolumn{2}{|c|}{ Regional lymph nodes (N) } \\
\hline No & $30(75 \%)$ \\
\hline N1 & $6(15 \%)$ \\
\hline N2 & $4(10 \%)$ \\
\hline \multicolumn{2}{|l|}{ Distant metastases (M) } \\
\hline Mo & $40(100 \%)$ \\
\hline M1 & 0 \\
\hline \multicolumn{2}{|c|}{ Chemotherapy/ neoadjuvant } \\
\hline No & $40(100 \%)$ \\
\hline yes & $0(0 \%)$ \\
\hline KRAS mut & $14(35 \%)$ \\
\hline KRAS wilde type & $7(17,5 \%)$ \\
\hline BRAF mut & $2(5 \%)$ \\
\hline BRAF wild type & 38 (95\%) \\
\hline
\end{tabular}

\section{Cell culture}

All cell lines (SW480, SW620, RKO, HCT116, HT29) derived from human colon cancer were used between 18 and 24 passages, and cultured in Dulbecco's modified Eagle medium (DMEM; Gibco) supplemented with 10\% (v/v) fetal bovine serum, $1 \mathrm{mmol} / \mathrm{L}$ l-glutamine, $1 \mathrm{mmol} /$ $\mathrm{L}$ sodium pyruvate, $0.1 \mathrm{mmol} / \mathrm{L}$ non-essential amino acids, and $100 \mathrm{U} / \mathrm{mL}$ ) antibiotics (penicillin and streptomycin) at $37^{\circ} \mathrm{C}$ in $5 \% \mathrm{CO} 2$.

\section{Animals}

Male and female C57BL/6 S1PR2 ${ }^{-/-}$mice aged 5-12 weeks old (generated by the team of Dr. Richard L. Proia, NIH, Bethesda, MD) were maintained according to national (D.Lgs 26/2014) and international animal care criteria and used to generate S1PR2 ${ }^{-/-}$and S1PR2 ${ }^{+/+}$littermates in the facility of Humanitas Clinical and Research Center. Female and male C57BL/6 Apc ${ }^{\mathrm{min} /+}$ aged 5-12 mice were purchased from the Jackson Laboratory (Stock No: 002020). The double transgenic mouse S1PR2 ${ }^{-/-} \mathrm{Apc}^{\mathrm{min} /+}$ was generated in the facility of the Humanitas Clinical and Research Center by crossbreeding S1PR2 ${ }^{-/-}$and $\mathrm{Apc}^{\mathrm{min} /+}$ mice. Athymic female CD-1 nude mice (Strain code: 086) were purchased from the Charles River Laboratories. All animals were fed a standard diet and housed in standard polypropylene mouse cages on sawdust bedding. Rooms were kept at $23^{\circ} \mathrm{C}$ and maintained on a 12-h light and 12-h dark cycle. All experiments were performed accordingly with the approval from the ethics committees of the Humanitas Clinical and Research Center, in agreement with national (D.Lgs 26/2014) and international animal care criteria. The genotypes were determined by PCR analysis of genomic DNA extracted from tail biopsies by $\mathrm{NaOH} 60$ $\mathrm{Mm}$ tail lysis. The primer sequences used for the genotyping of the S1PR2 gene were: 5' - GCA GTG ACA AAA GCT GCC GAA TGC TG-3', 5' - AGA TGG TGA CCA CGC AGA GCA CGT AG - 3' and 5'- TGA CCG CTT CTT CGT GCT TTA CGG TAT - 3. The sequences of primers used for the genotyping of the Apc gene were $5^{\prime}$ GCC ATC CCT TCA CGT TAG -3', 5' - TTC CAC TTT GGC ATA AGG $\mathrm{C}-3^{\prime}$ and $5^{\prime}-\mathrm{GTG}$ CAA TCC ATC TTG TTC AAT -3 '.

\section{Immunohistochemistry staining}

Murine and human samples were fixed in $4 \%$ formalin, processed, paraffin-embedded, and sectioned in $2 \mu \mathrm{m}$ slides. The colonic and intestinal paraffin-embedded tissue slides were deparaffinized, dehydrated with ethanol, and stained with hematoxylin (Dako) and eosin (Diapath) for the single-blinded histological evaluation of the inflammation (Rachmilewitz score) and tumor count or immune-stained. The staining for S1PR2 on murine and human tissue samples was carried out by heating the sections in $10 \mathrm{mM}$ citrate buffer ( $\mathrm{pH}$ 6.0). The endogenous peroxidase activity 
was inactivated in hydrogen peroxide $3 \%$ for $20 \mathrm{~min}$, and the endogenous mouse IgG and non-specific background were blocked by incubating $30 \mathrm{~min}$ in Rodent Block M (Biocare Medical) or Background Sniper (Biocare Medical) respectively murine and human sections. The primary antibody used for the S1PR2 staining was the anti-mouse/human rabbit S1PR2 antibody (Acris;1:200); for $1 \mathrm{~h}$ at RT. For the primary antibody detection, the $\mathrm{MACH} 1$ Universal HRP-Polymer (Biocare Medical) and the Betazoid DAB Chromogen Kit (Biocare Medical) have been used. Primary antibodies against Lgr5-GPR49 (Abcam;1:20) were incubated for $2 \mathrm{~h}$ at RT in Da Vinci Diluent (Biocare Medical); whereas anti-GFP biotin-conjugated (Invitrogen;1:500), Olfm4 (Cell Signaling; 1:400), Ki67 (Abcam;1:800), Caspase-3 (Cell Signaling; 1:800); CD45 (BD Pharmingen ${ }^{\mathrm{tw}}$; 1:100), $\beta$ Catenin (Abcam; 1:800)1 h at RT. Finally, antiBrdU (Serotec; 1:600) was incubated $40 \mathrm{~min}$ in Da Vinci Green Diluent (Biocare Medical).

\section{Statistical analysis}

Statistical significance was performed using GraphPad Prism 8 (GraphPad software San Diego, CA). The significance of data was evaluated using Paired Student ttests for comparisons between 2 means. Two-sided nonparametric Mann-Whitney test was used when there was no assumption of normal distribution. One- and Two-way ANOVA tests with Bonferroni's correction were used to compare the means of 2 or more groups. $P$ values below 0.05 were considered to be significant.

\section{Results}

\section{Reduced to the lost expression of S1PR2 in colorectal} cancer

To investigate the involvement of S1PR1, S1PR2, and S1PR3 in CRC, we firstly analyzed their mRNA levels in a homogenous cohort of CRC patients (within stages II and III). In the normal mucosa, expression levels of S1PR1 were higher compared to S1PR2 and S1PR3 levels, whereas S1PR2 and S1PR3 expression were comparable to each other/similar (Fig. 1a). Noticeably, in CRC samples, S1PR2 was significantly decreased as compared to normal mucosa $(p=0.043)$, whereas no difference was observed for S1PR1 and S1PR3 levels (Fig. 1a), indicating that only S1PR2 expression is reduced in CRC. Unexpectedly, no difference in the levels of S1P ligand was found between tumor and adjacent healthy tissue (Fig. S1). To address S1PR2 involvement in $\mathrm{CRC}$, we first quantified protein levels, which confirmed the drastic reduction of S1PR2 expression in the tumor (TN0) compared to matched normal mucosa $(p<0.01)$ (Fig. 1b), and second we characterized the tissue distribution of the receptor. Although different cell types, including monocytes and endothelial cells, express S1PR2 in the healthy mucosa (Fig. 1c), we found that S1PR2 was strongly present in the epithelial compartment. Specifically, it was more expressed in differentiated luminal/apical epithelial cells compared to undifferentiated cells residing at the bottom of the crypts (Fig. 1c). The comparison analysis of S1PR2 between the epithelial compartment and the whole tissue confirmed that the receptor is constitutively present on the healthy epithelium and strongly down-regulated on tumor cells (Fig. 1d). To further confirm the above data, we analyzed S1PR2 expression in 40 primary CRC samples and adjacent normal mucosa (Table 1), as well as in a tissue microarray (TMA) cohort consisted of 36 CRC tumors. S1PR2 immunostaining enforced the evidence of its marked reduction in tumor lesions, where it was confined to the epithelial compartment, displaying a heterogeneous modulation varying from a low (intensity score 3 ) or moderate reduction (intensity score 1-2) to a complete loss (intensity score 0 ) of the receptor in CRC tissues compared to adjacent normal mucosa (Fig. 1e). Based on a score of immunoreactivity that combines intensity and percentage of S1PR2 immunoreactivity (Supplementary Table 1), 25 $(32,89 \%)$ out of 76 patients presented no reactivity (score 0); 23 (30,26\%) displayed a low (score 1-2); 19 (25\%) a medium (score $3-4)$ and only $9(11,85 \%)$ a high (score 5-6) reaction comparable to healthy tissue (Fig. 1f), with no correlation with CRC stage ( $p=0.4338$ ) (Fig. 1g). Of relevance, we observed a strong significant reduced immunoreactivity for S1PR2 in CRC samples carrying KRAS mutation $(p<0.0001)$ (Fig. 1g).

\section{Genetic ablation of S1PR2 increases the susceptibility to develop neoplastic lesions in an in vivo model of colitis- associated colorectal cancer}

To explore the functional involvement of S1PR2 in CRC development, we took advantage of a mouse model of colitis-associated cancer induced in S1PR2 knockout $\left(\mathrm{S}_{\mathrm{PR}} 2^{-/-}\right.$or KO) mice. S1PR2 ${ }^{-/-}$mice did not show any significant worsening neither in the inflammatory clinical parameters (such as body weight and disease activity index, DAI) nor in the inflammation score compared to S1PR2 $2^{+/+}$ (Fig. 2a-c). These data were consistent with the results obtained in the acute colitis model, displaying no differences between S1PR2 ${ }^{-/-}$and S1PR2 ${ }^{+/+}$littermates, thus confirming that the loss of S1PR2 does not affect mouse susceptibility to DSS-induced colitis (Fig. S2a-c). In support of this, the analysis of infiltrating CD4-positive $\mathrm{T}$ cells combined with the systemic levels of inflammatory cytokines, including IL- 6 and IFN $\gamma$, did not reveal significant differences between the two groups (Fig. S2e-f). On the other hand, $\mathrm{S}_{\mathrm{PRR}} 2^{-/-}$mice exhibited a higher tumor incidence than $\mathrm{S} 1 P R 2^{+/+}$mice $(100 \%$ vs. $63 \% ; p=0.034)$ Fig. 2 d. Furthermore, both endoscopic and microscopic examination revealed that S1PR2-deficient developed a significantly higher number of tumors compared to littermate's WT animals $(p<0.001$ and $p=0.028$, respectively; Fig. 2e $u p$ panel and Fig. 2f) with increased serum levels of IL-17A, 


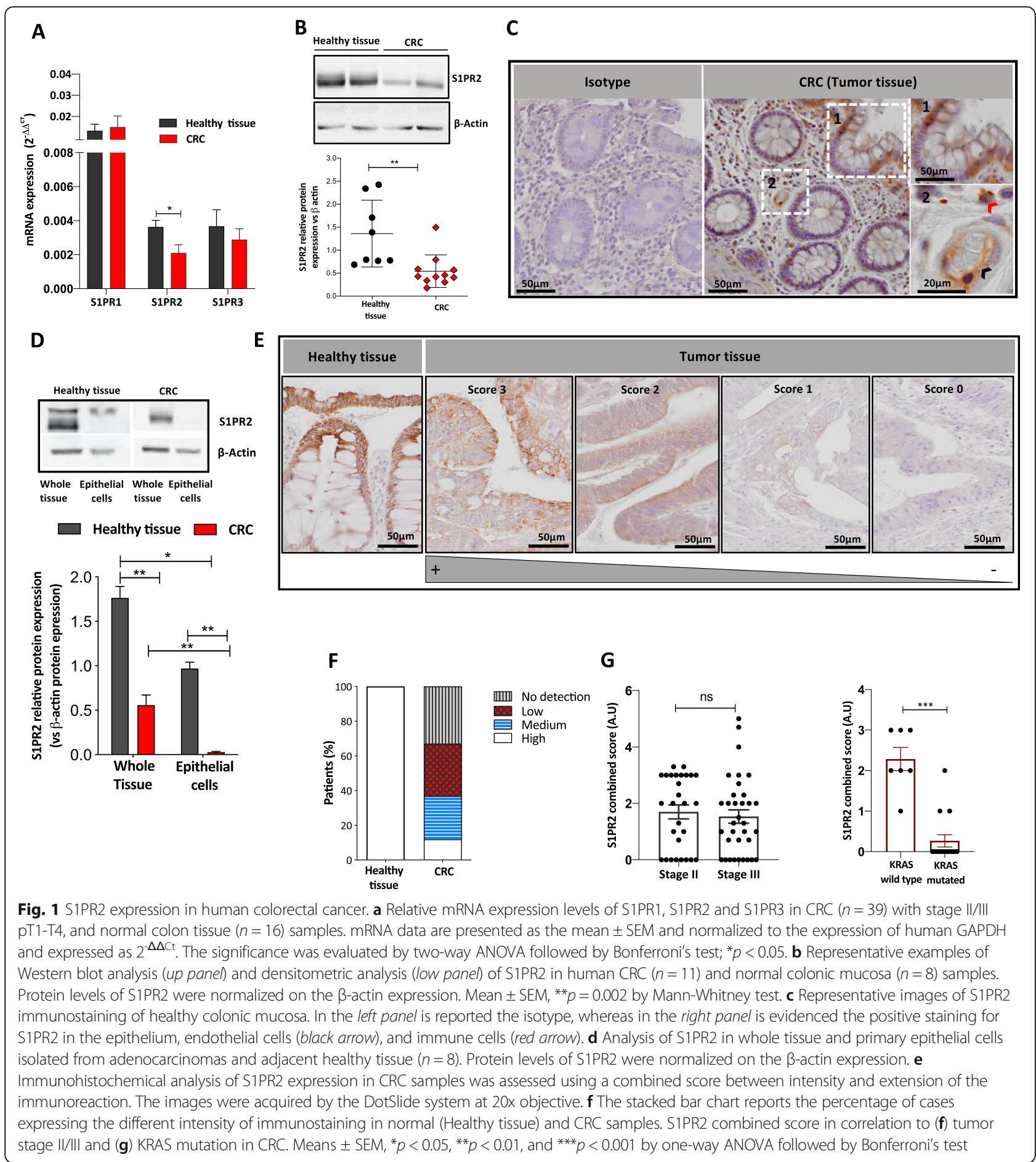

which it has been reported to promote tumor growth (Fig. S2f) [23]. Besides, the histological analysis highlighted a marked increased number of high-grade adenomas (HGA) $\left(1.3 \pm 2.109 \mathrm{~S} 1 P R 2^{-/-}\right.$vs. $0.3 \pm 0.483 \mathrm{~S} 1 \mathrm{PR} 2^{+/+}$mice, $p<$ 0.05 ) with a diameter between $0.3-0.4 \mathrm{~mm}$ and an increased number of carcinomas with diameter $>0.4 \mathrm{~mm}$ in $\mathrm{S}_{\mathrm{PR}} 2^{-/-}$compared to S1PR2 ${ }^{+/+}$mice $\left(2.5 \pm 3.6 \mathrm{~S}_{\mathrm{PR}} 2^{-/-}\right.$ vs. $1 \pm 1.2 \mathrm{~S} 1 \mathrm{PR} 2^{+/+}$mice, $p<0.05$ ) (Fig. $2 \mathrm{e}$ middle panels and Fig. $2 \mathrm{~g}$ ). The difference in the number of low-grade adenomas (LGA) between the two groups did not reach significance $\left(0.3 \pm 0.8 \mathrm{~S}_{\mathrm{PR}} 2^{-/-}\right.$vs. $0.3 \pm 0.6 \mathrm{~S}_{\mathrm{PR} 2}{ }^{+/+}$ mice, $p=0.1$ ) (Fig. S2d). Altogether, these data point to an enhanced cancer susceptibility, coupled to a faster/higher tumor growth rate in the S1PR2 ${ }^{-1-}$ background under 


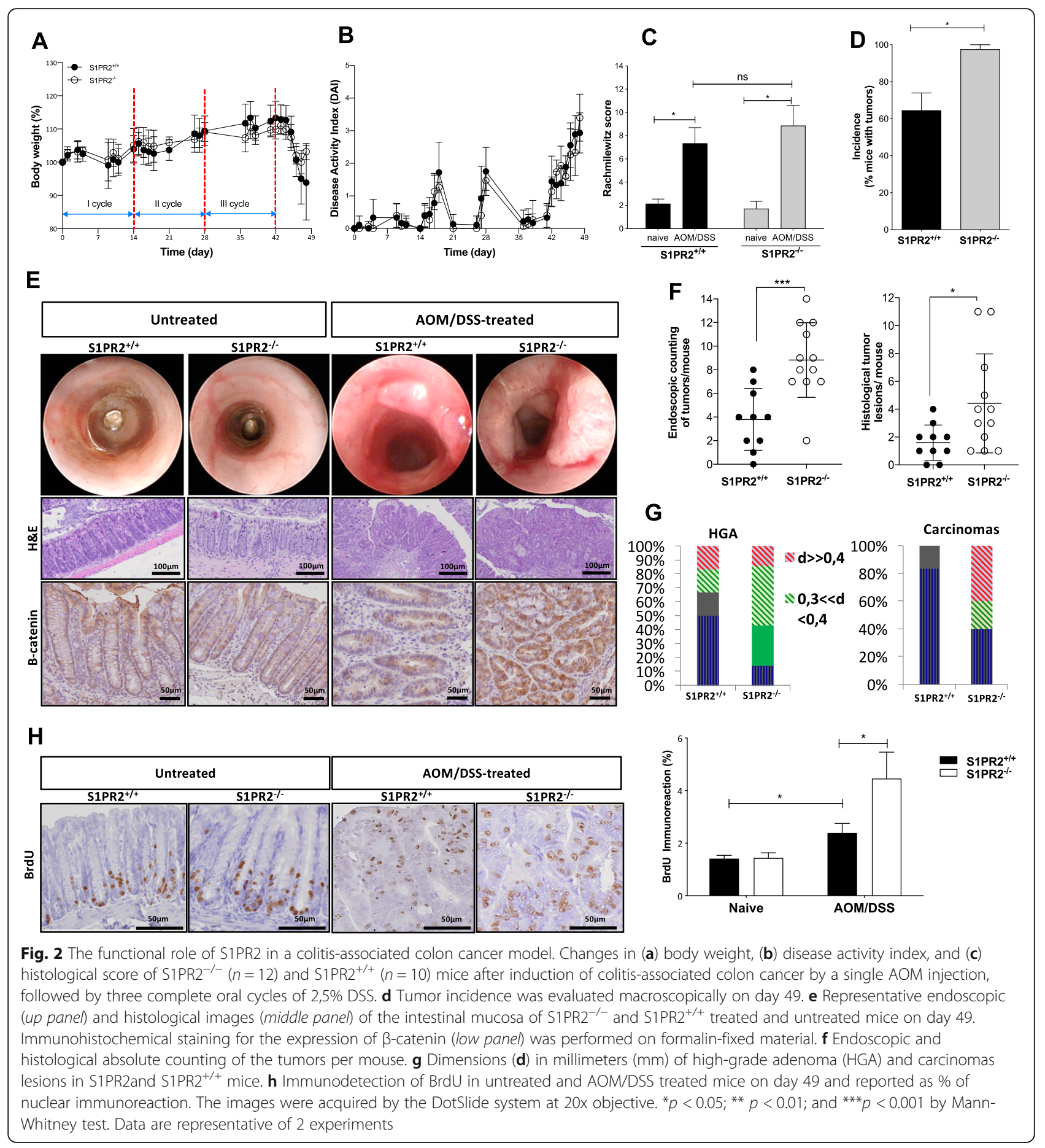

inflammatory conditions. Interestingly, the immunostaining for nuclear $B$-catenin was strongly positive in S1PR2 deficient mice compared to littermate WT mice (Fig. 2e), low panels). We next assessed whether the higher incidence of tumors in S1PR2 ${ }^{-1-}$ was also associated with a deregulated cell growth by intraperitoneally injecting BrdU $24 \mathrm{~h}$ before sacrifice. No difference was observed in healthy conditions between naive and tumor-bearing mice. In contrast, S1PR2 ${ }^{-/-}$tumor-bearing mice displayed an increased cell proliferation in tumor lesions compared to tumor-bearing S1PR2 ${ }^{+/+}$ones (Fig. 2h). The immunoexpression of anti-caspase 3 showed lower apoptotic cells in the tumor region compared to healthy surrounding regions of both S1PR2 ${ }^{+/+}$and S1PR2 ${ }^{-/-}$mice, indicating an enhanced survival of cancer cells (Fig. S3). However, the comparable survival rate observed between 
the two groups excludes a function of S1PR2 in controlling cell survival (Fig. S3).

\section{Loss of S1PR2 following APC mutation in colon carcinogenesis}

To further gain deeper insight into the role of S1PR2 in intestinal tumorigenesis, we also exploited an $\mathrm{Apc}^{\mathrm{Min} /+}$ mouse model that spontaneously develop multiple polyps in the small intestine [24]. S1PR2 deficiency in $\mathrm{Apc}^{\mathrm{min} /+}$ at 21 weeks old led to a significant increase of total tumor load over the entire gastrointestinal tract compared with their littermates S1PR2 ${ }^{+/+} \mathrm{Apc}^{\mathrm{min} /+}$ mice $(p<0.05)$ (Fig. 3a), which was well evident in the distal colon $(p=0.033)$ (Fig. 3b-c). In keeping with the observation in the DSS mouse model, we also observed a significant increase in the size of tumors in S1PR2 ${ }^{-/-} \mathrm{Apc}^{\mathrm{min} /+}$ compared to $\mathrm{S}_{\mathrm{PR} 2}{ }^{+/+} \mathrm{Apc}-$ $\mathrm{min} /+$ mice $(p=0.005)$ (Fig. 3c). In parallel, histologic examination highlighted a significantly higher number of carcinomas in S1PR2 ${ }^{-/-} \mathrm{Apc}^{\mathrm{min} /+}(2.40 \pm 0.51)$ compared to $\mathrm{S} 1 P R 2^{+/+} \mathrm{Apc}^{\mathrm{min} /+}$ mice $p=0.041$ (Fig. 3d). No difference was observed in LGA and HGA lesions number between the two groups (Fig. 3d). Accordingly, the Ki67 immunostaining showed a significantly increased cell proliferation in the colon of $\mathrm{S}_{\mathrm{PR}}{ }^{-/-} \mathrm{Apc}^{\mathrm{min} /+}$ compared to $\mathrm{S}_{1 \mathrm{PR} 2}{ }^{+/+} \mathrm{Apc}^{\mathrm{min} /+}$ mice (Fig. 3e) $(p=0.02)$. We found no difference in the small intestine tumor burden between the two groups (Fig. 3e). To address the role of S1PR2 during the early phases of tumor development, we inhibited pharmacologically S1PR2 in Apc ${ }^{\mathrm{Min} /+}$ mice at 10 weeks of age, before the appearance of both intestinal and colonic tumors, by the specific S1PR2 inhibitor (JTE013). JTE103 inhibitor accelerated tumor formation in $\mathrm{Apc}^{\mathrm{min} /+}$ mice in comparison to the vehicle (Fig. 3f) along the gastrointestinal tract. Moreover, while vehicle-treated $\mathrm{Apc}^{\mathrm{min} /+}$ mice developed only low-grade adenomas, the $\mathrm{Apc}^{\mathrm{min} /+}$ mice treated with the JTE013 inhibitor broadened high-grade adenomas and carcinomas (Fig. 3g), corroborating the loss of S1PR2 as an accelerator of tumor development and de-differentiation. S1PR2 immune-histochemical analysis in intestinal tissue of $\mathrm{Apc}^{\mathrm{min} /+}$ mice revealed a strong decrease of the receptor in the epithelial compartment of both high-grade adenomas and carcinomas compared to the normal epithelium (Fig. 3h).

\section{Loss of S1PR2 is an early event in the pathogenesis of colorectal cancer}

To validate this feature in humans, we analyzed S1PR2 expression in 5 human tubulovillous adenomas with moderate focal dysplasia, which is considered as an early precancerous lesion. All adenoma samples showed a significant reduction of S1PR2 compared to healthy mucosa (Fig. 3h-i), thus corroborating the hypothesis that the loss of S1PR2 in the epithelial compartment plays a key role in colorectal tumorigenesis and that it likely occurs in the early phase of cancer development.

\section{The overexpression of S1PR2 reduces the tumorigenicity of human CRC-derived epithelial cells in vivo}

To gain insight into the mechanisms by which the loss of S1PR2 promotes tumorigenesis, we explored the role of S1PR2 as a brake of tumor proliferation and a potential tumor suppressor gene in vivo. To this end, we firstly examined the endogenous expression of S1PR2 in four metastatic colon cancer cells SW620, RKO, HCT116, and HT29. In line with our previous data, S1PR2 expression was deficient in all cancer cells (Fig. S4a). Then, to test whether S1PR2 acts as a brake of tumor proliferation, we used lentivirus-mediated overexpression of S1PR2 in RKO (RKO-S1PR2-OE), which exhibited, at least in our hands, the highest infection efficiency among all cell lines negative for S1PR2. Overexpression efficiency was verified by RT-PCR (Fig. 4a). The effect of S1PR2 overexpression on the in vivo tumor cell growth was measured over 23 days after subcutaneous injection of RKO cells in female CD-1 nude mice. S1PR2 overexpression attenuated tumor growth with statistical significance $(p<0.05)$ compared to the scramble (Fig. 4b). Cell cycle analysis on the recovered tumors by flow cytometry demonstrated that most RKO cells overexpressing S1PR2 arrested at the G0/G1 phase, while a substantially higher fraction of cells from scramble tumors were in $\mathrm{S}$ and G2/M phases compared to S1PR2 overexpressing ones $(p<0.05)$ (Fig. $4 \mathrm{c})$. Based on in vivo experiments in which the loss of S1PR2 promoted the pathological accumulation of nuclear $ß$-catenin that, in turn, can control cell cycle, we examined whether S1PR2 exerted a direct role in this event. Interestingly, in contrast to scramble cells, RKO-S1PR2-OE displayed significantly higher levels of Axis inhibition protein 2 (Axin2) gene (Fig. 4d) that enhances the formation of the beta-catenin destruction complex and therefore prevents the nuclear translocation of $\beta$-catenin.

S1PR2 has been shown to inhibit cell migration in cancer cell lines $[19,20]$. To address whether S1PR2overexpression affected migratory and invasive properties of metastatic RKO cells, we performed transwell migration and invasion assays and analyzed the expression of some genes that support invasive capacities. S1PR2- overexpression did not affect the in vitro migratory capacity of RKO cells (Fig. S4b) neither in the mRNA expression levels of matrix metalloproteinases such as MMP1 and 2 (Fig. S4c), both genes involved in the distant metastasis development in CRC [25]. In line with these features, no difference was found between RKO scramble and RKO S1PR2 OE cells in distant organs such as the liver, mesenteric lymph nodes, adipose tissue, and colon (Fig. S4d) of mouse xenograft model. Overall, these findings supported the key role of S1PR2 in arresting tumor growth and excluded its 


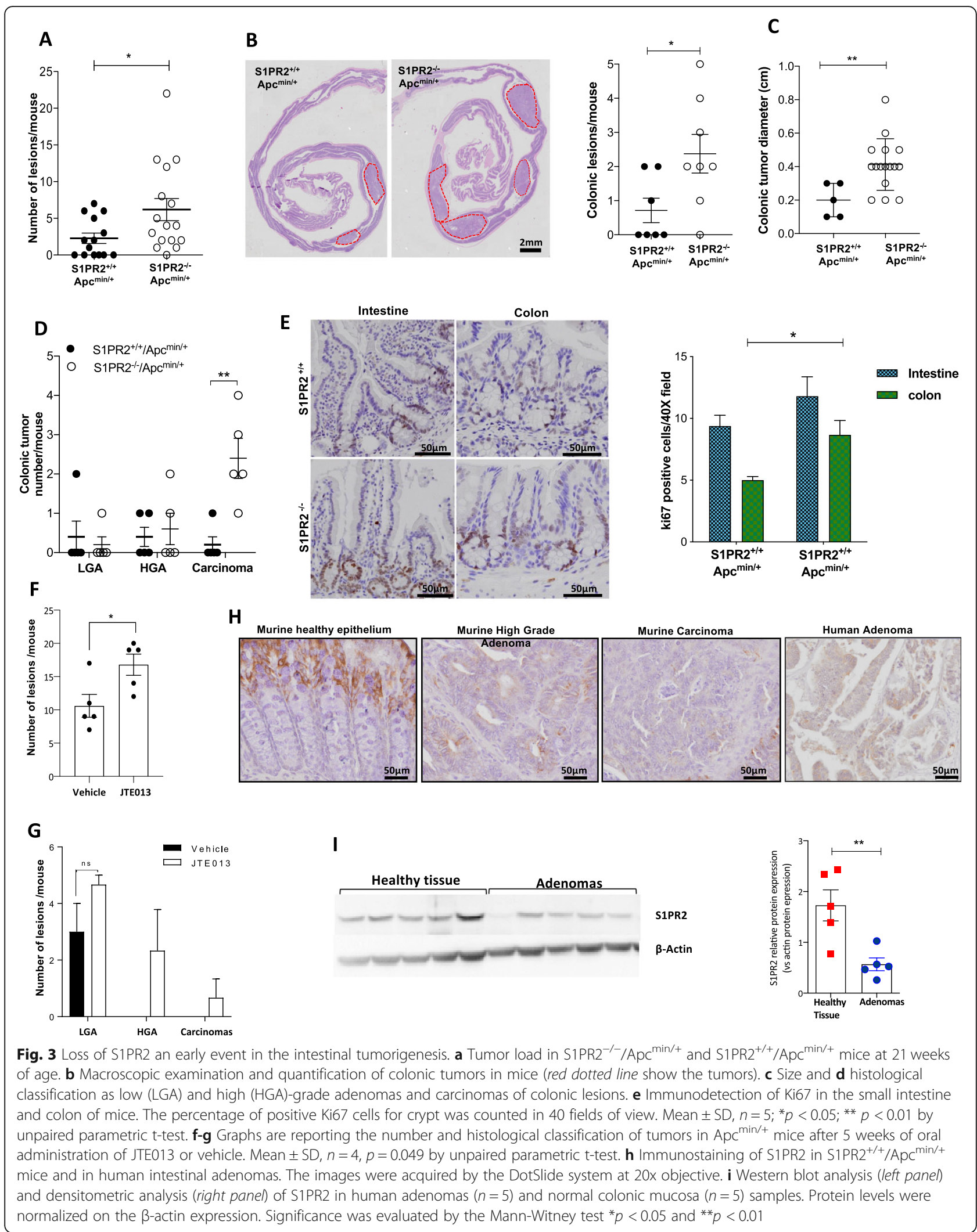




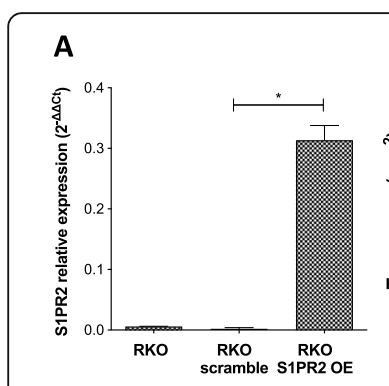

\section{B}
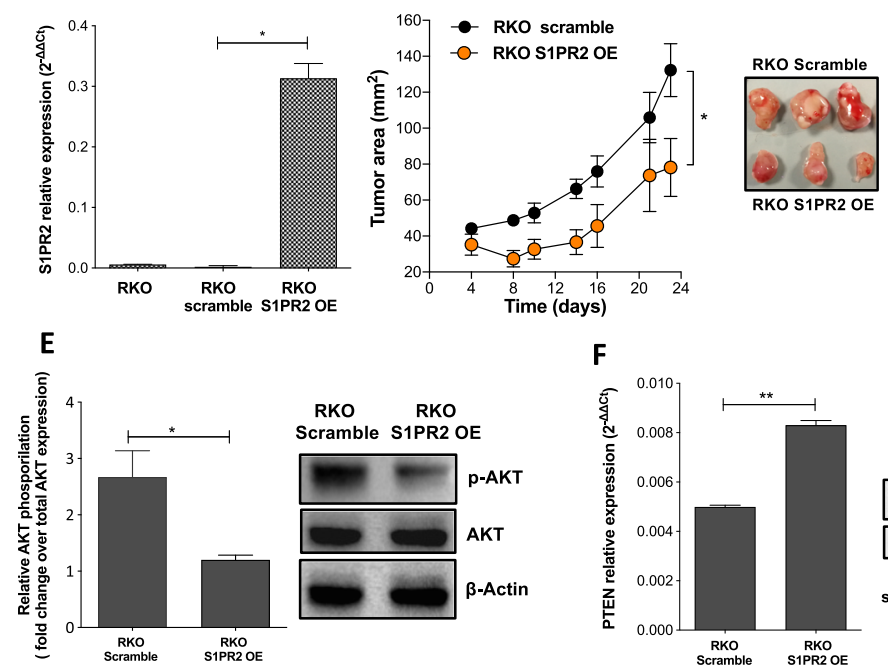
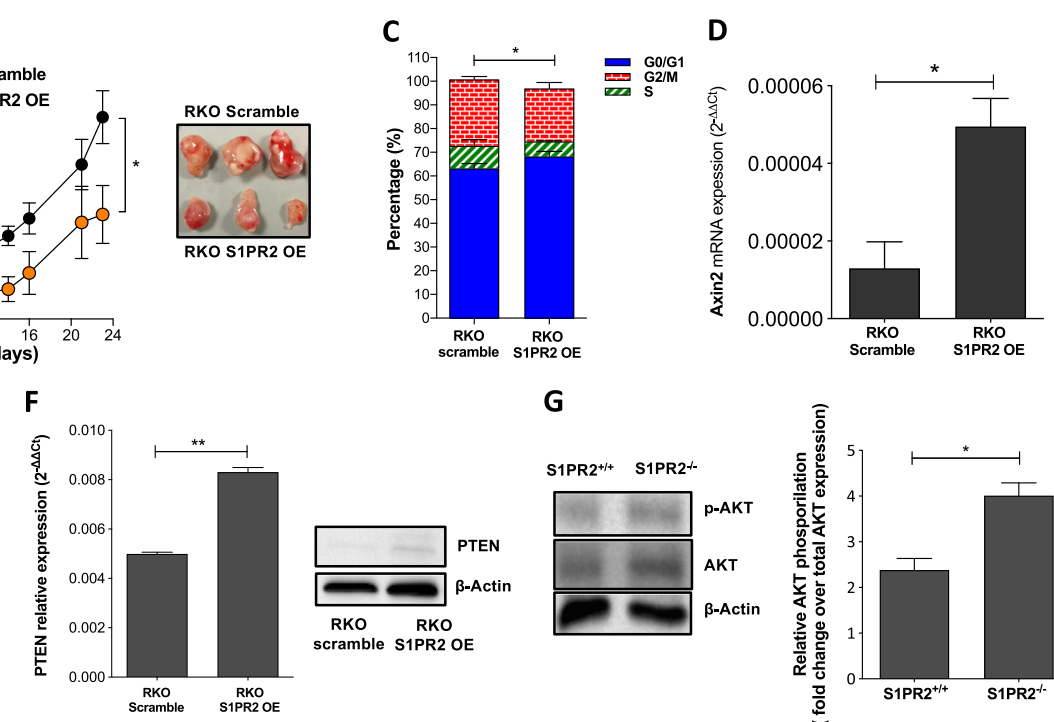

$\mathbf{G}$

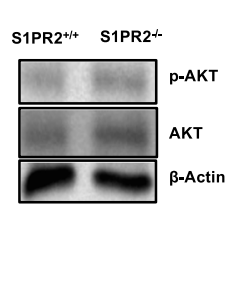

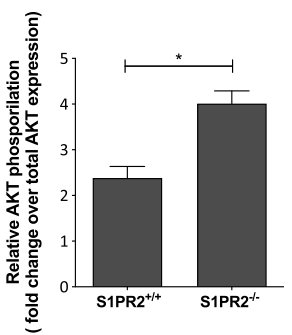

Fig. 4 Cellular processes and pathways impacted by S1PR2. a Relative mRNA levels of S1PR2 in the RKO cancer cell line before and after overexpression (OE) of S1PR2. b In vivo tumor growth of S1PR2-overexpressing GFP-RKO $\left(3 \times 10^{6}\right)$ vs. scramble cells over 23 days after injection. $\mathbf{c}$ Cell cycle analysis on recovered RKO-derived tumors. d Relative mRNA levels of Axin2 in RKO cells. e Western blot analysis (left panel) and densitometry (right panel) analysis of total (AKT) and phosphorylated AKT (p-AKT) in RKO cells. f mRNA (right panel) and protein (right panel) levels of PTEN. $\mathbf{g}$ Western blot (left panel) and densitometry (right panel) analysis of phosphorylated AKT ( $p$-AKT) in the mucosa of AOM/DSS treated $\mathrm{S} 1 \mathrm{PR}^{-/-}$and S1PR2 ${ }^{+/+}$mice. mRNA is mean $\pm \mathrm{SEM}$, normalized to the expression of GAPDH and expressed as $2^{-\Delta \mathrm{Ct}}$. The significance was evaluated by the Mann-Witney test, whereas the cell cycle by one-way ANOVA followed by Bonferroni's test; ${ }^{*} p<0.05 ;{ }^{* *} p<0.01$. Data are representative of 2 independent experiments; $n=4$

potential function in controlling the migratory capacity of epithelial tumor cells. Recently S1PR2 has been involved in the growth of hepatocellular carcinoma cells through the activation of PI3K/AKT signaling [26]. To investigate whether, in CRC cells, the modulation of S1PR2 can also drive the activation of the PI3K/AKT pathway, which is highly expressed in the RKO cell line [27], we quantified the protein levels of the phosphorylated AKT in RKO scramble and RKO S1PR2 OE cells. The overexpression of S1PR2 significantly reduced the phosphorylation of AKT (Fig. 4e). It augmented both mRNA and protein levels of Phosphatase and tensin homolog deleted on chromosome ten (PTEN), a negative regulator of the PI3K/AKT pathway (Fig. 4f). These results point out S1PR2 as a regulator of PTEN. To validate this hypothesis in an in vivo tumor model, we quantified pAKT in S1PR2 ${ }^{+/}$and S1PR1 $1^{-/-}$ tumor-bearing mice. As expected, the loss of S1PR2 augmented AKT levels and its phosphorylation in the mucosa of $\mathrm{KO}$ mice (Fig. 4g).

\section{S1PR2 inhibition impacts intestinal stem cell expansion}

The observation that the S1PR2 receptor is mainly expressed at the top of the intestinal crypts, while its expression is lower at the bottom where to reside intestinal stem cells, may support a differential expression of S1PR2 between differentiated intestinal epithelial and stem cells.

To verify whether S1PR2 is functionally involved in the proliferation and differentiation of intestinal stem cells, organoids isolated from naive WT mice were maintained in vitro for 6 days in the absence or presence of JTE013. Typically, intestinal organoids cultures tend to exhibit extensive budding of crypt-like domains (Fig. 5a up panels). In the presence of JTE013, organoids appeared with more cyst-like morphology characterized by a small number of uncomplete branches (Fig. 5a low panels). The roundshape of organoids raised the suspicion that JTE013 could prevent the differentiation of epithelial cells. Indeed, the levels of Olfm4 and Lgr5 stemness markers were significantly higher after JTE013 compared to untreated organoids (Fig. 5b), proving that the loss of S1PR2 maintains the organoids in an undifferentiated status. To gain deep insight into this aspect, we analyzed the expression of S1PR2 in stem (EpCAM+Lgr5-GFP+) and differentiated (EpCAM+Lgr5-GFP-) intestinal epithelial cells isolated from Lgr5-EGFP-IRES-creERT2 mice (Fig. 5c). Accordingly, EpCAM+Lgr5-GFP+ stem cells expressed lower levels of S1PR2 compared to differentiated cells (EpCAM+ Lgr5-GFP-) (Fig. 5d). In addition, Lgr5 + GFP immunostaining confirmed an increased number of Lgr5 positive cells in S1PR2 ${ }^{-/}$mice compared to their littermates Lgr5EGFP-S1PR2 $^{+/+}$(Fig. 5e).

\section{Loss of S1PR2 impairs mucosal regeneration in vivo}

To assess whether the deregulation of intestinal stem cell proliferation and differentiation participates in the impairment of mucosal regeneration in S1PR2 deficient 


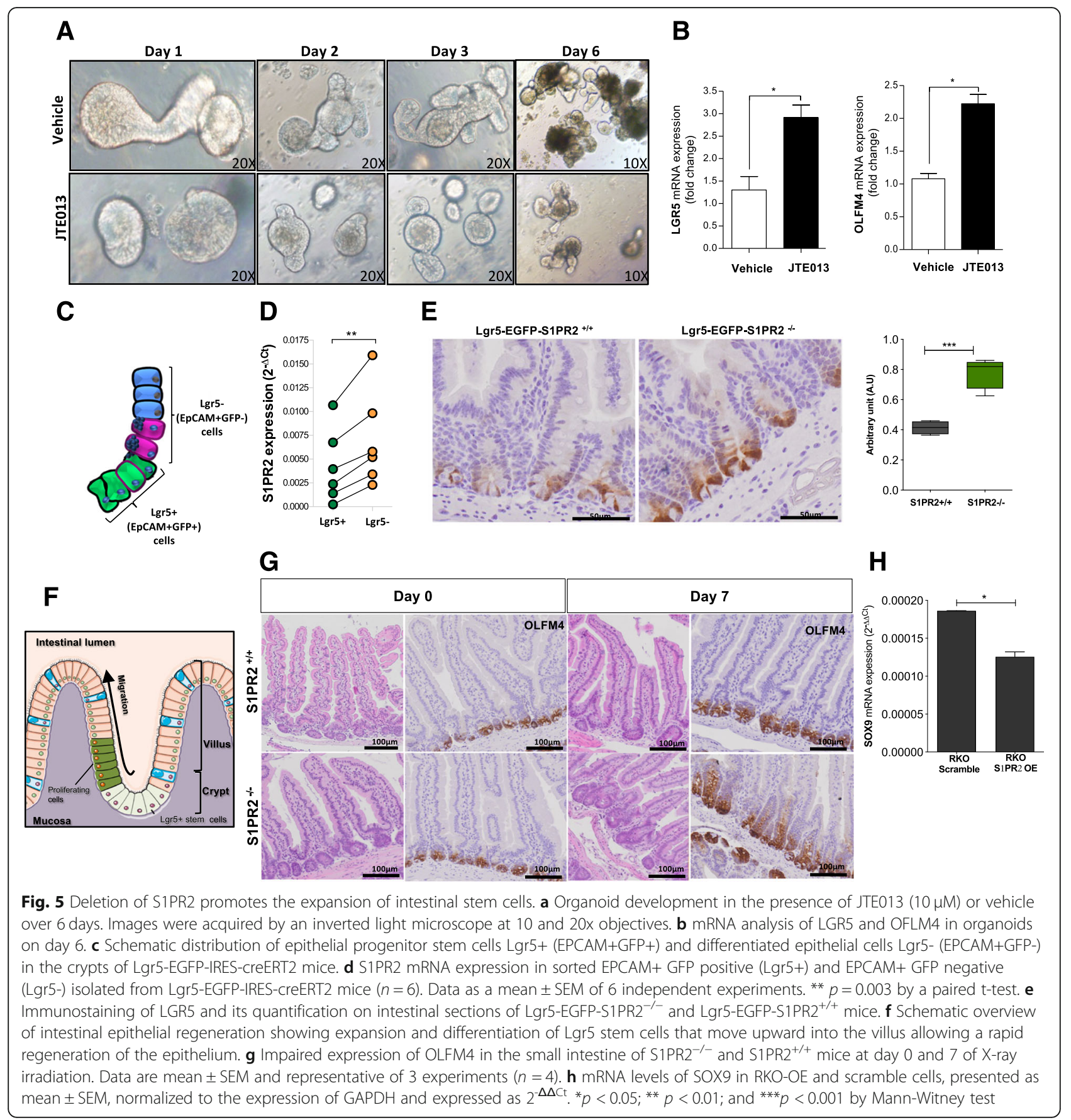

mice in vivo, which may contribute to intestinal tumorigenesis, we analyzed the regeneration of mucosal structure in $\mathrm{S} 1 \mathrm{PR} 2^{-/-}$and S1PR2 ${ }^{+/+}$mice after irradiation. Based on previous studies showing the time of mucosal regeneration following the irradiation [28], the destruction of the normal crypt-villus axis starts after 2 days in association with the expansion of undifferentiated Lgr5+ cells for replacing proliferating cells that, within 6-7 days, renew the intestinal mucosa structure by migrating from the bottom to the top along the crypt-villus axis (Fig. 5f). Both S1PR2 ${ }^{-/-}$ and S1PR2 ${ }^{+/+}$mice displayed substantial bodyweight loss within 7 days after irradiation, reflecting the damage to the intestinal mucosa (Fig. S4). After this time, both groups of mice started to gain their body weight in support of the recovery of mucosal damage. Although no difference was observed in the bodyweight recovery between S1PR2 ${ }^{+/+}$ and S1PR2 ${ }^{-/-}$mice (Fig. S4), the intestinal mucosa structure presented differently (Fig. $5 \mathrm{~g}$ ). Despite the presence of signs of a regenerative process still in progress, the mucosa of S1PR2 ${ }^{+/+}$mice recovered intestinal damage. It restored 
intestinal integrity by normalizing the villus height and crypt depth. Differently, the mucosa of S1PR2 ${ }^{-l-}$ mice, while showing a recovery of villi height, displayed elongated and enlarged crypts characterized by an increased number of undifferentiated cells, as evidenced by the strong immune-positivity for Oflm4 (Fig. $5 \mathrm{~g}$ ). To further corroborate the key role of S1PR2 in arresting the expansion of intestinal stem cells, we analyzed in RKO-S1PR2$\mathrm{OE}$ and scramble cells the expression of transcription factor Sex-determining region Y (SRY)-box 9 (SOX9), which is linked to stem cell maintenance [29] and implicated in CRC. The overexpression of S1PR2 reduced significantly SOX9 levels compared to RKO scramble cells (Fig. 5h), supporting S1PR2 as a brake for the expansion of intestinal stem cells.

\section{Discussion}

The relevance of the S1P pathway in the development of the CRC has emerged in the last years [10, 12]. However, the overall function of the S1PRs in colorectal tumorigenesis is still controversial $[15,16]$ and not entirely understood. Our current observations revealed: i) a not significant modulation of S1P levels in CRC patients; ii) higher expression of S1PR1 among the receptors in the normal mucosa; iii) a marked decrease only of S1PR2 in primary CRC already at an early phase (adenoma) of tumor development. Accordingly, S1PR2 deficient mice displayed increased susceptibility to experimental models of CRC. Although various cell types can express S1PR2 in the healthy mucosa, the modulation of the receptor in CRC was confined to the epithelium compartment. A recent study has demonstrated that S1PR2 on intestinal epithelial cells regulates epithelial barrier by preventing $\mathrm{CD} 4+\mathrm{T}$-cell proliferation [22]. Nevertheless, its function in epithelial cells is scanty. We showed for the first time that S1PR2 is strongly expressed by differentiated epithelial cells at the upper region of both colon and intestinal crypts, but not at the base by undifferentiated stem cells, which are essential for the regeneration of the epithelium layer. The precise mechanisms that finely control the survival, proliferation and selfrenewal of stem cells remain largely unknown. However, perturbations to this delicate balance leading to an excessive self-renewal would expand the stem cell pool at the base of the crypt, increasing the risk of intestinal tumorigenesis [30, 31]. Specifically, targeted ablation of the Lgr5 stem cell population in cancerous tissues revealed that it is dispensable for primary tumor maintenance [32, 33]. Here, we demonstrated by in vitro and in vivo studies that the loss of S1PR2 promotes the expansion of Lgr5-expressing stem/progenitor cells in the gut. Its overexpression in RKO cells resulted in the reduction of SOX9, a marker linked to stem cell maintenance [29], and in an accumulation of cells in the G0/G1 phase and a concomitant reduction of cells in the $\mathrm{S}$ and $\mathrm{M}$ phases, supporting S1PR2 as a master switch of intestinal self-renewal and differentiation of intestinal stem cells. Wnt/ß-catenin signaling works as the primary driving force behind these processes in the intestinal crypts [34]. Lgr5 is a marker of intestinal stem cells with a welldefined function in the promotion of $\mathrm{Wnt} / \beta$-catenin signalling [35] via modulation of the expression of adenomatous polyposis coli (APC) protein and $\beta$-catenin [36].

Consistent with these data, in addition to increased Lgr5expressing stem cells, S1PR2 ${ }^{-/}$mice showed a higher nuclear $\beta$-catenin accumulation compared to wild type mice. In the canonical Wnt cascade, $\beta$-catenin is the key effector responsible for the transduction of the signal to the nucleus. It is maintained into the cytoplasm at low levels and targeted for ubiquitination and degradation by a "destruction complex" that contains APC protein [24]. By crossing mice carrying a mutation in Apc and S1PR2 deficient mice, we observed acceleration of tumor formation, corroborating the hypothesis that the cross-talk of S1PR2 with intracellular Wnt/ß-catenin signals can critically regulate proliferative responses and tumor development. Interestingly, Axin2, a negative regulator of the Wnt/ $\beta$-catenin signaling pathway, which promotes the phosphorylation and degradation of $\beta$ catenin [37], was significantly upregulated in the cells overexpressing S1PR2 compared to scramble cells. It is reasonable to hypothesize that targeting Axin 2 S1PR2 regulates the degradation of $\beta$-catenin, thus preventing the transcription of genes involved in CRC development. Several studies supported the anti-tumor function of the S1PR2 acting as a negative regulator of the proliferation and migration of cancer cells $[11,19,20,38]$. However, the modulation of S1PR2 did not impact the migratory properties of RKO cancer cells, thus indicating that the migration capacities of these cells are S1PR2-independent. S1PR2 may intersect Wnt signals alternatively by modulation of Phosphatidylinositide-3-kinase (PI3K) [39], which activates $\beta$-catenin mediated transcription through AKT phosphorylation [40]. Enhanced PI3K signaling, either by mutations or through the loss of expression of its antagonist PTEN, can be observed in a variety of human malignancies, including colon cancer [41, 42]. Accordingly, AKT is constitutively activated in the RKO cell line due to the inactivation of PTEN. Of note, AKT phosphorylation was significantly down-regulated after overexpression of S1PR2, which correlated with increased levels of PTEN, indicating a key role of S1PR2 in negatively controlling PI3K-AKT pathways. How relevant is S1P ligand or whether other ligands participate in the activation of PTEN in RKO cells need to be better addressed. The cellular stress observed in the RKO cells overexpressing S1PR2 when cultured in a complete deprivation of S1P allows us to speculate a crucial role of S1P ligand in the activities of these cells (data not shown). Consistent with in vitro finding, the mucosa of AOM/DSS $\mathrm{S} 1 P R 2^{-/-}$mice showed higher levels of phosphorylated AKT compared to that from S1PR2 ${ }^{+/+}$mice. 


\section{Conclusions}

Based on our observations, S1PR2 protein may contrast the intestinal tumorigenesis by promoting epithelial differentiation, preventing the expansion of stem cells, and blocking their malignant transformation through the suppression of $\beta$-catenin nuclear translocation and $\beta$-catenin transcriptional activity. Therefore, tumor cells gain a massive advantage by its loss of function. Nevertheless, naïve S1PR2 $2^{-/}$mice showed normal architecture of the gut without developing tumor formations within their lifetime. It is reasonable that the absence of spontaneous tumorigenesis in S1PR2 deficient mice could be due to possible compensatory effects involving other pathways in the normal state that fail upon inflammation or in association with additional mutations.

Particularly, S1PR2 expression negatively correlated with CRC mutated for KRAS, which is associated with poor patient prognosis in CRC and with the resistance to the therapy [43]. This finding raises S1PR2 as a useful marker for early identification of this molecular subgroup of CRC. How S1PR2 expression is linked to this subgroup needs to be clarified. Recently, it has been reported that CRC mutated for KRAS express different miRNA profiles [44], including miR-130a [45], which modulates S1PR2 expression. Indeed, the inhibition of miR-130a-3p by specific inhibitor augmented S1PR2 levels [46]. It is likely that in the initiation process of CRC, normal epithelial cells acquire oncogenic mutations through the interaction between internal and external factors that lead to the downregulation of S1PR2, which in turn triggers an excessive epithelial self-renewal and tumor development. Therefore, targeting of S1PR2 may be of therapeutic benefit for CRC expressing high Lgr5 and of a prevention strategy for CRC development.

\section{Supplementary Information}

The online version contains supplementary material available at https://doi. org/10.1186/s13046-020-01740-6.

\footnotetext{
Additional file 1: Supplementary Figure 1. S1P levels in human colorectal cancer. Quantification of Sphingosine 1 phosphate (S1P) in adenocarcinomas and healthy colon tissue by spectrometry assay $(n=7)$. The levels of S1P are reported as pmol/mg. Data are presented as the mean \pm SEM, and significance was evaluated by performing a nonparametric test.
}

Additional file 2: Supplementary Figure 2. Clinical parameters and inflammation score in S1PR2 ${ }^{-/-}$and S1PR2 ${ }^{+/+}$mice after DSS-induced colitis. Acute colitis was induced in S1PR2 ${ }^{-/-}$and S1PR2 ${ }^{+/+}$mice by adding filtered 3\% DSS to drinking water for 9 days. Representative graphs showing (A) the changes in body weight and (B) disease activity index (DAI) during the entire experiment. (C) The inflammatory status of the colonic mucosa was evaluated accordingly to the Rachmilewitz score by histological analysis. Data are presented as the mean \pm SEM, and significance was evaluated by the Mann-Whitney test. Data is representative of 3 experiments $(n=5)$. (D) Representative histological images of CD45 cells of the colonic mucosa by immunohistochemistry of S1PR2 ${ }^{-/-}$and S1PR2 ${ }^{+/+}$ mice after AOM/DSS-induced colitis-associated cancer. The images were acquired by the DotSlide system at 20x objective. The quantification of
CD45 is reported as the CD45 immunoreactive area/40X field. (E) Serum levels of IL-6, IFNy, and IL-17A in S1PR2 ${ }^{-/}$and S1PR2 ${ }^{+/+}$mice after AOM/ DSS-induced colitis-associated cancer. Data are presented as the mean \pm SEM, and significance was evaluated by the Mann-Whitney test. Data is representative of 2 experiments $(n=6)$. (F) Low-grade adenoma (LGA) in $\mathrm{S} 1 P R 2^{-/-}$and S1PR2 ${ }^{+/+}$mice after AOM/DSS induced colitis. S1PR2 ${ }^{-/-}$ $(n=12)$ and S1PR2 ${ }^{+/+}(n=10)$ mice. Means \pm SEM.

Additional file 3: Supplementary Figure 3. Analysis of survival rate of the colonic mucosa of S1PR2 ${ }^{-1-}$ and S1PR2 ${ }^{+/+}$mice after AOM/DSS induced colitis-associated cancer. The tissues (healthy and tumor regions) were evaluated by immunohistochemical analysis with an anti-cleaved caspase- 3 antibody. The images were acquired by the DotSlide system at 20x objective. Apoptotic cells (blue arrows) were examined microscopically at 40X magnification. Data are presented as the mean \pm SEM, and significance was evaluated by the Mann-Whitney test. Data is representative of 2 experiments $(n=6)$.

Additional file 4: Supplementary Figure 4. Gene expression analysis in colon-rectal cancer cell lines and in S1PR2-overexpressing RKO cells. (A) S1PR2 mRNA expression levels in the indicated CRC cell lines. (B) Representative images of migratory and invasive cells (magnification, $4 \mathrm{x}$ ) are shown. Cell migration and invasiveness were reported as the number of cells in 40 fields of view. (C) Relative expression of metalloproteinases 1-2 (MMP1-2) in S1PR2-overexpressing RKO and scramble cells by qRT-PCR (2 $-\triangle \triangle \mathrm{Ct}$ method). Data are shown as means \pm SEM and are representative of 2 independent experiments, each constituted by three replicates. (D) Ex vivo macroscopic examination of organs (liver, adipose tissue, mesenteric lymph nodes (MLN) and xenograft tumor) in nude mice injected with S1PR2-overexpressing and scramble cells by an imaging system (IVIS) using GFP labeled cells. Data are representative of 2 independent experiments; $n=4$

Additional file 5: Supplemental Figure 5. Bodyweight changes in ${\mathrm{S} 1 P R 2^{-/}}^{-1}$ and S1PR2 ${ }^{+/+}$mice after 7 days of X-ray irradiation at $9 \mathrm{~Gy}$. Data are presented as the mean $\pm S E M$, and significance was evaluated by the Mann-Whitney test. Each group of data is representative of 3 experiments $(n=4)$.

Additional file 6. Corresponds to supplementary information related to the material and methods.

\section{Abbreviations}

S1PR: Sphingosine-1-Phosphate Receptor; CRC: Colorectal Cancer; LGR5: Leucine-rich repeat-containing G-protein coupled receptor 5; EGFP: Enhanced Green Fluorescent Protein; APC: Adenomatous polyposis coli; Min: Multiple intestinal neoplasia; PTEN: Phosphatase and tensin homolog deleted on chromosome ten; S1P: Sphingosine-1-phosphate; STAT3: Signal transducer and activator of transcription 3; TMA: Tissue Microarray; KO: Knockout; DAI: Disease activity index; DSS: Dextran Sulfate Sodium; WT: Wild Type; HGA: High-grade adenomas; LGA: Low-grade adenomas; BrdU: Bromodeoxyuridine; OE: Overexpression; Axin2: Axis inhibition protein 2; MMP: Matrix metalloproteinase;

PI3K: Phosphatidylinositide-3-kinase; EpCAM: Epithelial cell adhesion molecule; IRES: Internal ribosome entry site; ERT2: Estrogen receptor 2; Oflm4: Olfactomedin 4; SRY: Sex-determining region Y; SOX9: Sexdetermining region Y (SRY)-box 9; AOM: Azoxymethane; miRNA: microRNA; RT-PCR: Reverse transcriptase-polymerase chain reaction; $\mathrm{p}$ AKT: Phosphorylated AKT; GAPDH: Glyceraldehyde 3-phosphate dehydrogenase

\section{Acknowledgments}

The authors thank Mrs. Ghada Shalaby for assistance with the English language editing of the manuscript.

\section{Authors' contributions}

Generation, collection, assembly, analysis and interpretation of data L.P.; Conceptualization, Investigation, Formal Analysis, Supervision, and Funding Acquisition, SV; Writing -Original Draft and Visualization, L.P., S.V.; Investigation, Methodology, Data Curation, and Formal Analysis, G.R., F.R., M.C., S.E., S.D., F.G., S.S; Methodology and Data Curation, P.C., S.R., A.P., V.A., B.R., A.A., T.C., F.U.; Resources, S.V., S.D.; Writing - Review \& Editing, S.V., S. D, A.S., L.L., A.M. All the authors read and approved the final manuscript. 


\section{Funding}

This research was supported by: Fondazione Cariplo per la Ricerca 2012/0678 to SV; Associazione Italiana Contro le Leucemie - Linfomi e Mieloma (AIRC) 17795 to SV; Associazione Italiana Contro le Leucemie - Linfomi e Mieloma (AIRC) 19229 to SD. Fondazione Umberto Veronesi to BR; Associazione Italiana Contro le Leucemie - Linfomi e Mieloma (AIRC) 16092 to LG; Esprinet SpA Italy.

\section{Availability of data and materials}

The datasets used and/or analyzed during the current study are available from the corresponding author on reasonable request.

\section{Ethics approval and consent to participate}

All participants provided informed written consent. The study protocol was approved by the Ethics Committee of Humanitas Clinical and Research Center-IRCCS (Rozzano, Italy)

\section{Consent for publication}

We have received consent from individual patients who have participated in this study. The consent forms will be provided upon request.

\section{Competing interests}

The authors declare that they have no competing interests.

\section{Author details}

${ }^{1}$ IBD Center, Department of Gastroenterology, Humanitas Clinical and Research Center-IRCCS, Rozzano, Italy. ${ }^{2}$ Department of Biomedical Sciences, Humanitas University, Via Rita Levi Montalcini, Pieve Emanuele, Italy. ${ }^{3}$ Department of Pathology, Humanitas Clinical, and Research Center-IRCCS, Milan, Italy. ${ }^{4}$ Area of Pathology, Department of Woman and Child Health and Public Health, Fondazione Policlinico Universitario A. Gemelli-IRCCS, Rome, Italy. ${ }^{5}$ Colon and Rectal Surgery Unit, Humanitas Clinical and Research Center-IRCCS, Rozzano, Italy. ${ }^{6}$ Department of Pharmacy, School of Medicine and Surgery, University of Naples Federico II, Naples, Italy. ${ }^{7}$ Laboratory of Molecular Gastroenterology, Department of Gastroenterology, Humanitas Clinical and Research Center IRCCS, Rozzano, Italy. ${ }^{8}$ Flow Cytometry Core, Humanitas Clinical and Research Center-IRCCS, Rozzano, Italy. ${ }^{9}$ Department of Pathology, Faculty of Medicine, University of Rijeka, Rijeka, Croatia. ${ }^{10}$ Department of Immunology and Inflammation, Humanitas Clinical and Research Center IRCCS, Rozzano, Italy. ${ }^{11}$ Centro di Riferimento Oncologico della Basilicata (IRCCS-CROB), Rionero in Vulture, Italy. ${ }^{12}$ Department of Medicine and Surgery, University of Parma, Parma, Italy.

Received: 7 August 2020 Accepted: 16 October 2020 Published online: 23 November 2020

\section{References}

1. Maceyka M, Harikumar KB, Milstien S, Spiegel S. Sphingosine-1-phosphate signaling and its role in disease. Trends Cell Biol. 2012;22(1):50-60 Available from: https://doi.org/10.1016/j.tcb.2011.09.003.

2. Nagahashi M, Abe M, Sakimura K, Takabe K, Wakai T. The role of sphingosine-1-phosphate in inflammation and cancer progression. Cancer Sci. 2018;109(12):3671-8.

3. Takabe K, Paugh SW, Milstien S, Spiegel S. Inside-out signaling of sphingosine-1-phosphate: therapeutic targets. Pharmacol Rev. 2008;60(2): $181-95$.

4. Danese S, Furfaro F, Vetrano S., Targeting S1P in Inflammatory Bowel Disease: New Avenues for Modulating Intestinal Leukocyte Migration, Journal of Crohn's and Colitis. 2018;12(suppl_2):S678-86.

5. Nagahashi M, Ramachandran S, Kim EY, Allegood JC, Rashid OM, Yamada A et al. Sphingosine-1-phosphate produced by sphingosine kinase 1 promotes breast cancer progression by stimulating angiogenesis and lymphangiogenesis. Cancer Res. 2012;72(3):726-35.

6. Weichand B, Popp R, Dziumbla S, Mora J, Strack E, Elwakeel E, et al. S1PR1 on tumor-associated macrophages promotes lymphangiogenesis and metastasis via NLRP3/LL-1B. J Exp Med. 2017;214(9):2695-713.

7. Dai L, Liu Y, Xie L, Wu X, Qiu L, Di W. Sphingosine kinase 1/sphingosine-1phosphate (S1P)/S1P receptor axis is involved in ovarian cancer angiogenesis. Oncotarget. 2017;8(43):74947-61.

8. Nagahashi M, Yamada A, Katsuta E, Aoyagi T, Huang WC, Terracina KP, et al. Targeting the SphK1/S1P/S1PR1 axis that links obesity, chronic inflammation, and breast cancer metastasis. Cancer Res. 2018;78(7):1713-25.
9. Liu YN, Zhang H, Zhang L, Cai TT, Huang DJ, He J, et al. Sphingosine 1 phosphate receptor-1 (S1P1) promotes tumor-associated regulatory T cell expansion: leading to poor survival in bladder cancer. Cell Death Dis. 2019; 10(2):50.

10. Lee H, Deng J, Kujawski M, Yang C, Liu Y, Herrmann A, et al. STAT3-induced S1PR1 expression is crucial for persistent STAT3 activation in tumors. Nat Med.2010;16(12):1421-8.

11. Yamashita H, Kitayama J, Shida D, Yamaguchi H, Mori K, Osada M, et al, Sphingosine 1-phosphate receptor expression profile in human gastric cancer cells: differential regulation on the migration and proliferation. J Surg Res. 2006;130(1):80-7.

12. Kawamori T, Kaneshiro T, Okumura M, Maalouf S, Uflacker A, Bielawski J, et al. Role for sphingosine kinase 1 in colon carcinogenesis. FASEB J. 2009; 23(2):405-14.

13. Keum NN, Giovannucci E. Global burden of colorectal cancer: emerging trends, risk factors and prevention strategies. Nat Rev Gastroenterol Hepatol. 2019; 16(12):713-32 Available from: https://doi.org/10.1038/s41575-019-0189-8.

14. Van Der Heijden M, Vermeulen L. Stem cells in homeostasis and cancer of the gut. Mol Cancer. 2019;18(1):1-15.

15. Shida D, Inoue S, Yoshida Y, Kodaka A, Tsuji T, Tsuiji M. Sphingosine kinase 1 is upregulated with lysophosphatidic acid receptor 2 in human colorectal cancer. World J Gastroenterol. 2016;22(8):2503-11.

16. Uranbileg B, Nishikawa T, Ikeda H, Kurano M, Sato M, Saigusa D, et al. Evidence Suggests Sphingosine 1-Phosphate Might Be Actively Generated, Degraded, and Transported to Extracellular Spaces With Increased S1P 2 and S1P 3 Expression in Colon Cancer. Clin Colorectal Cancer. 2018;17(2): e171-82.

17. Yamaguchi H, Kitayama J, Takuwa N, Arikawa K, Inoki I, Takehara K, et al. Sphinoosine-1-phosphate receptor subtype-specific positive and negative regulation of Rac and haematogenous metastasis of melanoma cells. Biochem J. 2003;374(3):715-22.

18. Arikawa K, Takuwa N, Yamaguchi H, Sugimoto N, Kitayama J, Nagawa H, et al. Ligand-dependent inhibition of B16 melanoma cell migration and invasion via endogenous S1P2 G protein-coupled receptor: requirement of inhibition of cellular Rac activity. J Biol Chem. 2003;278(35):32841-51.

19. Lepley D, Paik JH, Hla T, Ferrer F. The G protein-coupled receptor S1P2 regulates rho/rho kinase pathway to inhibit tumor cell migration. Cancer Res. 2005;65(9):3788-95.

20. Li MH, Sanchez T, Pappalardo A, Lynch KR, Hla T, Ferrer F. Induction of antiproliferative connective tissue growth factor expression in Wilms' tumor cells by sphingosine-1-phosphate receptor 2. Mol Cancer Res. 2008;6(10):1649-56.

21. Du W, Takuwa N, Yoshioka K, Okamoto Y, Gonda K, Sugihara K, et al. S1P2, the $\mathrm{G}$ protein-coupled receptor for sphingosine-1- phosphate, negatively regulates tumor angiogenesis and tumor growth in vivo in mice. Cancer Res. 2010;70(2):772-81.

22. Chen $T$, Lin $R$, Jin $S$, Chen $R$, Xue $H$, Ye H, et al. The Sphingosine-1phosphate/Sphingosine-1-phosphate receptor 2 Axis in intestinal epithelial cells regulates intestinal barrier function during intestinal epithelial cells-CD4 + T-cell interactions. Cell Physiol Biochem. 2018;48(3):1188-200.

23. De Simone V, Franzè E, Ronchetti G, Colantoni A, Fantini MC, Di Fusco D, et al. Th17-type cytokines, IL-6 and TNF-a synergistically activate STAT3 and NF-kB to promote colorectal cancer cell growth. Oncogene. 2015;34(27): 3493-503.

24. Moser AR, Luongo C, Gould KA, McNeley MK, Shoemaker AR, Dove WF. ApcMin: a mouse model for intestinal and mammary tumorigenesis. Eur $」$ Cancer. 1995;31(7-8):1061-4.

25. Wong JCT, Chan SK, Schaeffer DF, Sagaert X, Lim HJ, Kennecke H, et al. Absence of MMP2 expression correlates with poor clinical outcomes in rectal cancer, and is distinct from MMP1-related outcomes in colon cancer. Clin Cancer Res. 2011;17(12):4167-76.

26. Yin $Y, X u M, G a O J$, Li M. Alkaline ceramidase 3 promotes growth of hepatocellular carcinoma cells via regulating S1P/S1PR2/PI3K/AKT signaling. Pathol Res Pract. 2018;214(9):1381-7 Available from: https://doi.org/10.1016/ j.prp.2018.07.029.

27. Nemoto S, Nakamura M, Osawa Y, Kono S, Itoh Y, Okano Y, et al. Sphingosine kinase isoforms regulate oxaliplatin sensitivity of human colon cancer cells through ceramide accumulation and Akt activation. J Biol Chem. 2009;284(16):10422-32.

28. Metcalfe C, Kljavin NM, Ybarra R, De Sauvage FJ. Lgr5+ stem cells are indispensable for radiation-induced intestinal regeneration. Cell Stem Cell. 2014;14(2):149-59 Available from: https://doi.org/10.1016/j.stem.2013.11.008. 
29. Blache P, Van De Wetering M, Duluc I, Domon C, Berta P, Freund JN, et al. SOX9 is an intestine crypt transcription factor, is regulated by the Wnt pathway, and represses the CDX2 and MUC2 genes. J Cell Biol. 2004;166(1):37-47.

30. Barker N, Ridgway RA, Van Es JH, Van De Wetering M, Begthel H, Van Den Born M, et al. Crypt stem cells as the cells-of-origin of intestinal cancer. Nature. 2009:457(7229):608-11.

31. Morgan RG, Mortensson E, Williams AC. Targeting LGR5 in colorectal Cancer: therapeutic gold or too plastic? Br J Cancer. 2018;118(11):1410-8 Available from: https://doi.org/10.1038/s41416-018-0118-6.

32. Junttila MR, Mao W, Wang X, Wang BE, Pham T, Flygare J, et al. Targeting LGR5+ cells with an antibody-drug conjugate for the treatment of colon cancer. Sci Transl Med. 2015;7(314):1-12.

33. Gong X, Azhdarinia A, Ghosh SC, Xiong W, An Z, Liu Q, et al. LGR5-targeted antibody-drug conjugate eradicates gastrointestinal tumors and prevents recurrence. Mol Cancer Ther. 2016;15(7):1580-90.

34. Clevers H, Nusse R. Wnt/ $\beta$-catenin signaling and disease. Cell. 2012;149(6): 1192-205.

35. De Lau W, Barker N, Low TY, Koo BK, Li VSW, Teunissen H, et al. Lgr5 homologues associate with Wnt receptors and mediate R-spondin signalling. Nature. 2011;476(7360):293-7.

36. Lin Y, Wu T, Yao Q, Zi S, Cui L, Yang M, et al. LGR5 promotes the proliferation of colorectal cancer cells via the Wnt/ $\beta$-catenin signaling pathway. Oncol Lett. 2015;9(6):2859-63.

37. Jho E, Zhang T, Domon C, Joo C-K, Freund J-N, Costantini F. Wnt/B-Catenin/ Tcf Signaling Induces the Transcription of Axin2, a Negative Regulator of the Signaling Pathway. Mol Cell Biol. 2002;22(4):1172-83.

38. Stelling A, Hashwah H, Bertram K, Manz MG, Tzankov A, Müller A. The tumor suppressive TGF-b/SMAD1/S1PR2 signaling axis is recurrently inactivated in diffuse large B-cell lymphoma. Blood. 2018;131(20):2235-46.

39. Sanchez T, Thangada S, Wu MT, Kontos CD, Wu D, Wu H, et al. PTEN as an effector in the signaling of antimigratory $\mathrm{G}$ protein-coupled receptor. Proc Natl Acad Sci U S A. 2005;102(12):4312-7.

40. Persad A, Venkateswaran G, Hao L, Garcia ME, Yoon J, Sidhu J, et al. Active $\beta$-catenin is regulated by the PTEN/PI3 kinase pathway: a role for protein phosphatase PP2A. Genes Cancer. 2016;7(11-12):368-82.

41. Vivanco I, Sawyers CL. The phosphatidylinositol 3-kinase-AKT pathway in human cancer. Nat Rev Cancer. 2002:2:489-501.

42. Samuels Y, Wang Z, Bardelli A, Silliman N, Ptak J, Szabo S, et al. High Frequency of Mutations of the PIK3CA Gene in Human Cancers. Science (80- ). 2004;304(5670):554.

43. Phipps Al, Buchanan DD, Makar KW, Win AK, Baron JA, Lindor NM, et al. KRAS-mutation status in relation to colorectal cancer survival: The joint impact of correlated tumour markers. Br J Cancer. 2013; 108(8):1757-64.

44. Lundberg I V., Wikberg ML, Ljuslinder I, Li X, Myte R, Zingmark C, et al. MicroRNA expression in KRAS- and BRAF-mutated colorectal cancers. Anticancer Res. 2018:38(2):677-83.

45. Chen W, Tong K, Yu J. MicroRNA-130a is upregulated in colorectal cancer and promotes cell growth and motility by directly targeting forkhead box F2. Mol Med Rep. 2017;16(4):5241-8.

46. Fan A, Wang Q, Yuan Y, Cheng J, Chen L, Guo X, et al. Liver x receptor- $a$ and miR-130a-3p regulate expression of sphingosine 1-phosphate receptor 2 in human umbilical vein endothelial cells. Am J Physiol - Cell Physiol. 2016;310(3):C216-26

\section{Publisher's Note}

Springer Nature remains neutral with regard to jurisdictional claims in published maps and institutional affiliations.

Ready to submit your research? Choose BMC and benefit from:

- fast, convenient online submission

- thorough peer review by experienced researchers in your field

- rapid publication on acceptance

- support for research data, including large and complex data types

- gold Open Access which fosters wider collaboration and increased citations

- maximum visibility for your research: over $100 \mathrm{M}$ website views per year

At BMC, research is always in progress.

Learn more biomedcentral.com/submissions 